\title{
Effect of terbutaline on bronchoconstriction induced by nebulised pentamidine
}

\author{
T R Leigh, J Wiggins, B G Gazzard, J V Collins
}

\begin{abstract}
The severity, duration, and reversibility of pentamidine induced bronchial narrowing was studied with and without pretreatment with nebulised terbutaline $10 \mathrm{mg}$ in an open study of 40 patients seropositive for the human immunodeficiency virus (HIV). All subjects received pentamidine $300 \mathrm{mg}$ in $5 \mathrm{ml}$ water via an Acorn System 22 jet nebuliser. The forced expiratory volume in one second $\left(F E V_{1}\right)$ fell in all 20 patients given pentamidine alone, the mean maximum fall being $20.6 \%$. In the 20 patients given pentamidine preceded by nebulised terbutaline the mean maximum fall in $F E V_{1}$ was $4 \%$; three subjects had a fall in $\mathrm{FEV}_{1}$ of more than $10 \%$.
\end{abstract}

Nebulised pentamidine isethionate is now established for the prophylaxis and treatment of Pneumocystis carinii pneumonia in patients with human immunodeficiency virus infection. It may, however, cause bronchial narrowing in these patients. ${ }^{12}$ The purpose of this study was to define the frequency, magnitude, duration, and response to terbutaline of airflow limitation induced in HIV positive patients by the inhalation of nebulised pentamidine isethionate.

\section{Methods}

We studied 40 homosexual, HIV positive men (mean age 35.6 (range 24-56) years) with no past history of chronic lung disease. Seventeen were cigarette smokers. All were receiving fortnightly treatment with pentamidine isethionate (Pentacarinat, Rhône-PoulencRorer: $300 \mathrm{mg}$ in $5 \mathrm{ml}$ of water) delivered by an Acorn System 22 jet nebuliser (Medic-Aid, Pagham, Sussex) at a flow rate of $8 \mathrm{l} / \mathrm{min}$ (particle mass median diameter (MMD) 3 $\mu \mathrm{m})$. Twenty patients received nebulised pentamidine alone, 13 for primary prophylaxis as they had not had pneumocystis pneumonia; the remaining 20 patients (16 for primary prophylaxis) inhaled $10 \mathrm{mg}$ nebulised terbutaline sulphate in $2 \mathrm{ml}$ normal saline 15 minutes before receiving nebulised pentamidine.

$\mathrm{FEV}_{1}$ was measured before treatment (mean duration of pentamidine administration 10 minutes) and one, two, five, 10, and 30 minutes after completion of the inhalation.

Statistical analyses were performed with the Mann-Whitney and Wilcoxon rank sum tests.

\section{Results}

PRETREATMENT FEV

The forced expiratory volume in one second $\left(\mathrm{FEV}_{1}\right)$ was normal in most patients in both groups (mean $\mathrm{FEV}_{1}$ : pentamidine group $102 \%$ predicted (range $70-141 \%$ ), pentamidine + terbutaline group $106 \%$ predicted (range $65-$ $133 \%)$ ). There was no significant difference in $\mathrm{FEV}_{1}$ between patients having primary and those having secondary pneumocystis pneumonia prophylaxis ( $107 \%$ v $95 \%$ predicted).

EFFECT OF PENTAMIDINE WITH AND WITHOUT TERBUTALINE

$\mathrm{FEV}_{1}$ fell in all 20 subjects treated with pentamidine alone (mean maximum fall $21 \%$, range $8-62 \% ; p<0.001)$. The mean fall in $\mathrm{FEV}_{1}$ was maximal five minutes after inhalation of pentamidine (mean fall $19 \% ; p<0.001$ ), and it was still reduced by $16 \%$ at 30 minutes (figure). The fall in $\mathrm{FEV}_{1}$ varied widely between patients; a fall of $15 \%$ or more occurred in 13 of the 20 patients at some time after they had pentamidine. The response was no different in patients having primary and secondary pneumocystis pneumonia prophylaxis, nor did the number of previous episodes of pneumocystis pneumonia make any difference.

There was a fall in FEV in most of the group pretreated with terbutaline (mean maximum change in $\mathrm{FEV}_{1}=-4.3 \%$, range +16.6 to $-22.6 \%, p<0.005)$ but it was less than that seen with pentamidine alone $(p<0.001)$. Three of these patients had a $10 \%$ or greater fall in $\mathrm{FEV}_{1}$; in two this was still present 30 minutes after the pentamidine inhalation.

\section{Discussion}

Bronchial narrowing with pentamidine isethionate may be partially abolished by pretreatment with nebulised beta agonists. ${ }^{23} \mathrm{~A}$ fall in $\mathrm{FEV}_{1}$ occurred rapidly in all patients who did not receive terbutaline. The range and time course of bronchial narrowing was variable, but unrelated to the number of previous episodes of pneumocystis pneumonia. There was a trend suggesting that smokers might be more susceptible to the effects of pentamidine than nonsmokers (mean fall in $\mathrm{FEV}_{1} 25 \% v 19 \%$ ), but this was not significant.

The mechanism of pentamidine induced bronchial narrowing is unknown, but is probably related to the deposition site and nature of the nebulised solution. The particle MMD of our nebuliser system was $3 \mu \mathrm{m}$. A smaller particle size would give greater distal deposition, ${ }^{4}$ and may account for reports of 
Relation between percentage fall in FEV, and time after pentamidine inhalation with and without pretreatment with terbutaline. Each point represents the group mean result and vertical bars represent standard errors

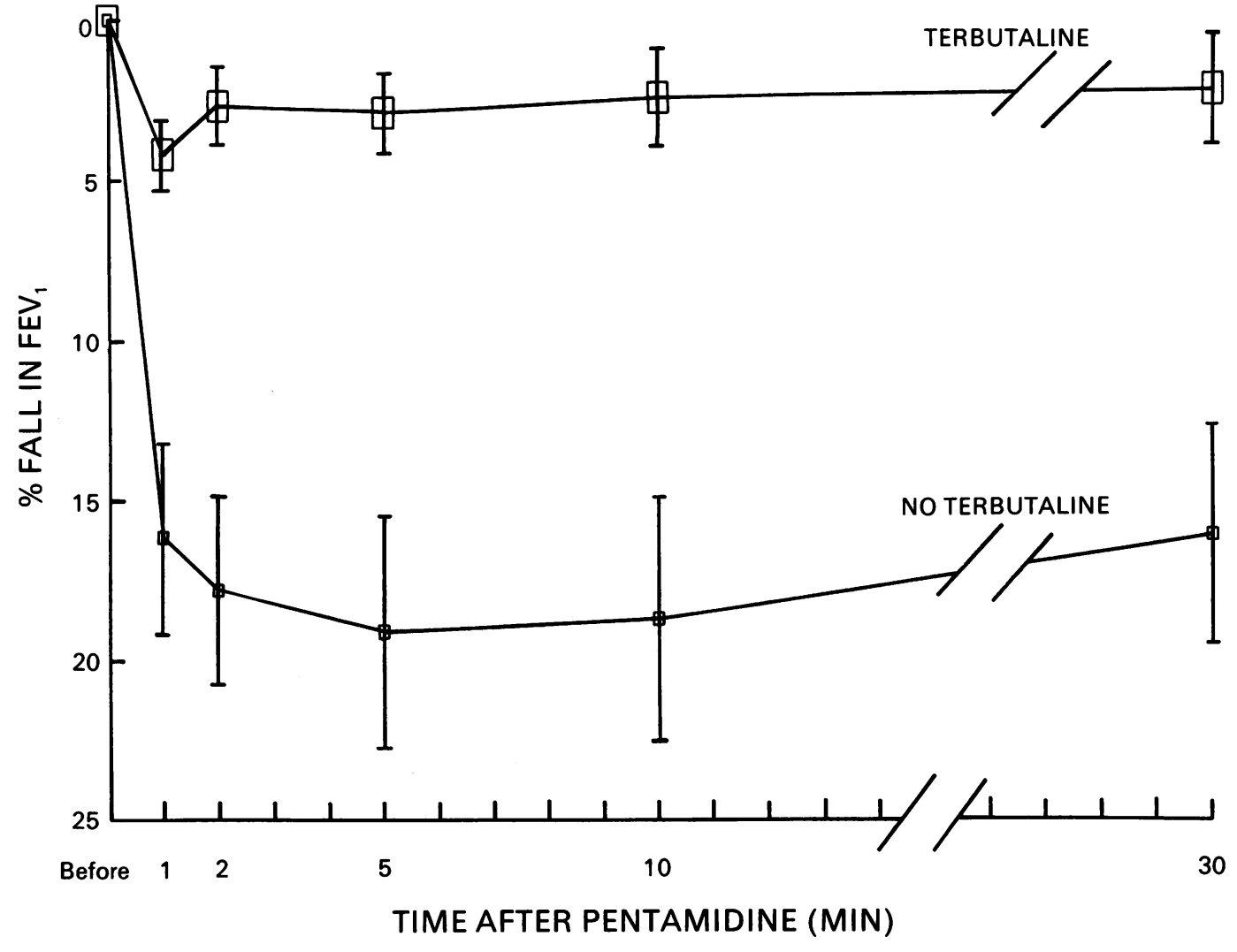

fewer side effects from nebulisers that produce smaller particles. ${ }^{5}$ The changes in $\mathrm{FEV}_{1}$ may result from rapid spasm of bronchial smooth muscle, local mucosal inflammatory response, direct histamine release, or platelet function inhibition.

Both moieties of pentamidine isethionate have been implicated in the genesis of airway narrowing, though in one study pentamidine isethionate and pentamidine gluconate caused no difference in toxicity, ${ }^{6}$ suggesting that pentamidine rather than isethionate is responsible for bronchial narrowing. The $\mathrm{pH}$ and osmolality of the nebulised solution might also be important. ${ }^{7}$ The $\mathrm{pH}$ of pentamidine isethionate is 4.5-6.0 (data on file, RhônePoulenc-Rorer), which is sufficiently acidic to cause bronchial irritation. Adjustment of this $\mathrm{pH}$, possibly by inert buffers, may reduce unwanted effects. When pentamidine is made into solution as recommended by the manufacturer it is sufficiently hypotonic to cause airway narrowing. The osmolality ranges from 128 mosmol/ $\mathrm{kg}$ (for $300 \mathrm{mg}$ pentamidine isethionate in $10 \mathrm{ml}$ water) to $294 \mathrm{mosmol} / \mathrm{kg}$ (for 300 $\mathrm{mg}$ pentamidine isethionate in $3 \mathrm{ml}$ water)
(Leigh et al, unpublished observations).

Thus pretreatment with $10 \mathrm{mg}$ nebulised terbutaline reduced the severity of falls in $\mathrm{FEV}_{1}$ seen with nebulised pentamidine but did not totally abolish them. Whether modification of the pentamidine solution and its mode of administration will reduce side effects more requires further investigation.

1 Thomas S, O'Doherty M, Bateman N. Pneumocystis carinii pneumonia. Aerosolised pentamidine gives effective

2 Smith DE, Herd D, Gazzard BG. Reversible bronchoconstriction with nebulised pentamidine. Lancet 1988; ii:905.

3 O'Doherty MJ, Page C, Bradbeer C, et al. Differences in relative efficiency of nebulisers for pentamidine administration. Lancet 1988;ii:1283-6. models for internal dosimetry of the human respiratory tract. Health Phys 1966;12:173-207.

5 Montgomery AB, Debs RJ, Luce JM, et al. Aerosolised pentamidine as sole therapy for Pneumocystis carinii pneumonia in patients with acquired immunodeficiency syndrome. Lancet 1987;ii:480-2.

6 Corkery KJ, Montgomery AB, Montanti R, Fine JM. Airway effects of aerosolized pentamidine isethionate [abstract]. Am Rev Respir Dis 1990;141:A152.

7 Beasley R, Rafferty P, Holgate ST. Adverse reactions to the non-drug constituents of nebuliser solutions. $\mathrm{Br} \mathrm{J} \mathrm{Clin}$ Pharmacol 1988;25:283-7. prophylaxis. $B M J$ 1990;300:211-2.

4 Task Group on Lung Dynamics. Deposition and retention 